\title{
SINTESIS NANOPARTIKEL MAGNETIT DENGAN METODE DEKOMPOSISI TERMA
}

\author{
(MAGNETITE NANOPARTICLE SYNTHESIS BY THERMAL \\ DECOMPOSITION METHODS)
}

\author{
Rahyani Ermawati dan Emmy Ratnawati \\ Balai Besar Kimia dan Kemasan, Kementerian Perindustrian \\ Jl. Balai Kimia 1, Pekayon, Pasar Rebo, Jakarta Timur \\ E-mail: ermakyoto@yahoo.com
}

Received 25 Maret 2011; revised 31 Maret 2011; accepted 11 April 2011

\begin{abstract}
ABSTRAK
Sintesis nanopartikel besi oksida, khususnya magnetit $\left(\mathrm{Fe}_{3} \mathrm{O}_{4}\right)$ telah berkembang dalam beberapa tahun terakhir ini. Hal ini disebabkan antara lain oleh adanya sifat supermagnetis yang dimiliki menyebabkan nanopartikel magnetit mendatangkan manfaat dalam aplikasinya. Masalah yang ada dalam sintesis nanopartikel oksida logam $\mathrm{Fe}_{3} \mathrm{O}_{4}$ adalah cara untuk memperoleh nanopartikel yang nondisperse dan tidak teraglomerasi dimana persyaratan ini diperlukan dalam aplikasi nanopartikel magnetit di berbagai bidang. Pada penelitian ini dilakukan sintesis nanopartikel $\mathrm{Fe}_{3} \mathrm{O}_{4}$ (magnetit) secara bottom-up dengan metode dekomposisi termal. Nanopartikel yang diperoleh dikarakterisasi dengan menggunakan alat PSA (Particle Size Analyzer), Benchtop microscope, SEM (Scanning Electron Microscope), kemudian dilakukan interpretasi terhadap hasil yang didapatkan. Dari hasil karakterisasi dapat disimpulkan bahwa proses dekomposisi termal dari $\mathrm{Fe}(\mathrm{III})$ acetylacetonate hingga $280^{\circ} \mathrm{C}$ menghasilkan $\mathrm{Fe}_{3} \mathrm{O}_{4}$ dengan distribusi ukuran partikel nano yang beragam. Diameter partikel $\mathrm{Fe}_{3} \mathrm{O}_{4}$ yang terbentuk berukuran $50,0 \mathrm{~nm}$ hingga $53,9 \mathrm{~nm}$. Bilangan distribusi tertinggi berada pada diameter 50,0 $\mathrm{nm}$ sebesar $69,27 \%$, dengan diameter partikel rata-rata sebesar $51,3 \mathrm{~nm}$.
\end{abstract}

Kata Kunci: Sintesis nanomaterial, Magnetit $\left(\mathrm{Fe}_{3} \mathrm{O}_{4}\right)$, Dekomposisi termal

\begin{abstract}
Synthesis of Ferri oxide magnetite $\left(\mathrm{Fe}_{3} \mathrm{O}_{4}\right)$ has been developed in recent years. The superparamagnetic properties on magnetite nanoparticle were widely used in industrial application. Problem in the synthesis of metal oxide nanoparticles is agglomeration of nanoparticles whereas dispersion of nanoparticles as a necessary requirement in a variety of applications. Synthesis of magnetite nanoparticle by bottom-up method using thermal decomposition was carried out in this research. Then the magnetic nanoparticle was characterized by using SEM (Scanning Electron Microscope) and PSA (Particle Size Analyzer). Based on the analysis, the result concludes that the process of thermal decomposition of $\mathrm{Fe}$ (III) acetylacetonate up to $280^{\circ} \mathrm{C}$ produced $\mathrm{Fe}_{3} \mathrm{O}_{4}$ nanoparticle with varying size distribution. The diameter size of particle $\mathrm{Fe}_{3} \mathrm{O}_{4}$ have range from $50,0 \mathrm{~nm}$ to 53,9 $\mathrm{nm}$. The number of distribution was $50,0 \mathrm{~nm}$ about $69,27 \%$ and mean of particle size was $51,3 \mathrm{~nm}$.
\end{abstract}

Key words: Nanomaterial synthesis, Magnetite $\left(\mathrm{Fe}_{3} \mathrm{O}_{4}\right)$, Thermal decomposition

\section{PENDAHULUAN}

Penelitian material menemukan area baru yang sangat mendasar dengan digunakannya orde ukuran nanometer $\left(10^{-9} \mathrm{~m}\right)$ sebagai penyusun terkecil material fungsional. Ukuran atau dimensi yang semakin kecil tersebut memberikan implikasi yang sangat luas dalam pengembangan metode penelitian material yang berakibat makin bertambah banyaknya penemuan pemanfaatan nanomaterial untuk kehidupan. Berkaitan dengan kebutuhan nanoteknologi, nanomaterial dapat memiliki wujud yang berbeda-beda seperti nanopowder, 
nanotube atau karena penyusunnya sehingga disebut nanokeramik, nanopolimer dan nanokomposit, atau dapat pula karena memiliki fungsi-fungsi yang spesifik seperti nanoelektronik, nanomedika, nanofotonik dan nanomagnetik.

Pengembangan nanoteknologi telah menjadi daya tarik baik bagi ilmuwan maupun pemerintah dengan melakukan kegiatan penelitian, termasuk pembuatan atau sintesis material nano. Pemanfaatan material berukuran nano menjanjikan peluang untuk menciptakan teknologi baru yang penerapannya diharapkan mampu membawa perubahan infrastruktur yang dramatis. Material nano merupakan susunan materi yang berukuran 1 nanometer hingga 100 nanometer (Brydson and Hammond 2005) menunjukkan karakteristik unik yang disebabkan oleh ukuran tersebut. Nanomaterial dapat dibuat dengan dua pendekatan, yaitu top - down (memperkecil) dan bottom - up (memperbesar).

Ada tiga cara yang dikenal untuk membuat nanomaterial dengan pendekatan top - down, yaitu penggilingan (milling), litografi dan machining. Sedangkan pendekatan bottom - up menggunakan cara Vapour Phase Deposition (VPD), deposisi dengan plasma, epitaksi berkas molekular (Molecular Beam Epitaxy, MBE), fasa basah, koloidal, sol-gel dan elektrodeposisi.

Studi dan sintesis tentang nanopartikel besi oksida, khususnya magnetit $\left(\mathrm{Fe}_{3} \mathrm{O}_{4}\right)$ telah berkembang dalam beberapa tahun terakhir ini. Hal ini disebabkan adanya sifat supermagnetis yang dimiliki menyebabkan nanopartikel magnetit mendatangkan manfaat dalam berbagai aplikasi di beberapa bidang. Di bidang medis, nanopartikel magnetit yang bersifat biocompatible dapat digunakan sebagai agent dalam bioimaging yaitu Magnetic Resonance Imaging (MRI) contrast agent, agent dalam Drug Delivery System baik dengan cara conjungation ataupun encapsulation agent dalam hyperthermia, misalnya untuk membunuh sel tumor secara thermogenesis dan agen dalam cell labelling.

Keuntungan yang diperoleh dari penggunaan nanopartikel magnetit di bidang medis adalah rasio antara luas permukaan dan volume partikel yang besar serta kemudahan untuk diakses ke jaringan tubuh. Aplikasi di bidang teknologi antara lain sebagai ferrofluid dalam rotary shaft scaling, oscillation dumping, dan position sensing dan sebagai material pada magnetic storage devices, magnetic refrigeration system. Aplikasi lainnya adalah sebagai pemisah logam dalam pengolahan limbah cair, sebagai lipida protein detector, katalis, enzym immobilizator dan biosensor. Nanopartikel $\mathrm{Fe}_{3} \mathrm{O}_{4}$ demikian luas manfaatnya dalam sains dan teknologi, sehingga pengembangan material baru ini sangatlah dibutuhkan baik menyangkut eksplorasi bahan baku, pengembangan metode sintesis, metode karakterisasi maupun aplikasinya. Dalam pengembangan metode diharapkan dapat dikembangkan metode sintesis yang menghasilkan produk berskala nano yang monodisperse dan tak teraglomerasi. Sifat monodisperse dibutuhkan untuk kemudahan aplikasinya. Sedangkan sifat tak teraglomerasi dibutuhkan agar diperoleh domain tunggal dari perilaku partikel-partikel tersebut. Nanomaterial dapat diketahui sifat-sifatnya melalui tahapan yang disebut karakterisasi. Sifat-sifat itu diantaranya adalah ukuran (dimensi) butir atau kristalnya, kelistrikan, kemagnetan dan kelarutannya yang dapat diungkap melalui pengukuran atau pengamatan menggunakan alat yang sesuai.

Pada penelitian ini akan dilakukan sintesis nanopartikel secara bottom-up, untuk partikel $\mathrm{Fe}_{3} \mathrm{O}_{4}$ (magnetit). Nanopartikel yang diperoleh dikarakterisasi dengan menggunakan alat $P S A$ (Particle Size Analyzer), Benchtop microscope semi SEM (Scanning Electron Microscope), kemudian dilakukan interpretasi terhadap hasil yang didapatkan.

\section{BAHAN METODE}

\section{Bahan}

Bahan yang dipakai pada penelitian ini adalah: $\mathrm{Fe}$ (III) acetylacetonate; 1,2 dodecanediol; asam oleat; diphenylether; etanol; dan heksana. Alat yang digunakan dalam penelitian ini adalah antara lain labu leher tiga, condensor, magnetic stirrer, hot plate, termometer, oil bath, beaker glass, pipet tetes, alumunium foil, $\mathrm{N}_{2}$ container tube, gelas ukur, erlenmeyer, sentrifusa, alat timbang, spatula, SEM (Scanning Electron Microscope), dan PSA (Particle Size Analyzer).

\section{Metode}

Sebanyak 0,7085 gram $\mathrm{Fe}(\mathrm{III})$ acetylacetonate (2 $\mathrm{mmol}) ; 2,0387$ gram

1,2 -dodecanediol (10 mmol); $2 \mathrm{~mL}$ asam oleat (6 mmol); $2 \mathrm{~mL}$ oleylamine $(6 \mathrm{mmol})$ dan $20 \mathrm{~mL}$ diphenylether dimasukkan ke dalam labu leher tiga untuk direflux dan di-stirrer selama 30 menit pada suhu $220^{\circ} \mathrm{C}$. Kemudian, larutan dipindahkan ke dalam erlenmeyer dan didinginkan hingga suhu kamar dengan pengaliran $N_{2}$. 
Setelah terbentuk larutan berwarna coklat kehitaman, ditambahkan $200 \mathrm{~mL}$ etanol dan didiamkan 1 jam hingga 2 jam pada suhu kamar untuk pengendapan.

Setelah terbentuk endapan berwarna coklat kehitaman, larutan disaring dengankertas saring Whatman 40. Endapan yang didapat dilarutkan kembali dengan heksana sehingga terbentuk lagi larutan berwarna coklat kehitaman. Larutan dibagi dua dan ditambahkan $2 \mathrm{~mL}$ etanol, kemudian disentrifusa 30 menit dengan 2000 rpm hingga 3000 rpm. Selanjutnya dilakukan pengukuran dengan PSA untuk mengetahui ukuran partikel. Sedangkan endapan yang terbentuk dicuci dengan etanol dan dikeringkan dan dilakukan pengukuran dengan SEM untuk mengetahui deskripsi morfologi.

Proses sintesis magnetit $\left(\mathrm{Fe}_{3} \mathrm{O}_{4}\right)$ dengan labu leher tiga pada suhu $280^{\circ} \mathrm{C}$ selama kurang lebih 1 jam 45 menit di atas magnetic stirrer dengan dialiri gas $\mathrm{N}_{2}$ dapat dilihat pada Gambar 1.

Reaksi proses pembuatan nanopartikel magnetit adalah sebagai berikut:

$$
\underset{(\mathrm{HO})_{2} \mathrm{CH}\left(\mathrm{CH}_{2}\right)_{10} \mathrm{CH}_{3}}{\stackrel{\left.\mathrm{CH}_{3} \mathrm{COCH}=\mathrm{C}(\mathrm{O}) \mathrm{CH}_{3}\right]_{2} \mathrm{Fe}}{\mathrm{CH}_{3}\left(\mathrm{CH}_{2}\right)_{7} \mathrm{CH}=\mathrm{CH}\left(\mathrm{CH}_{2}\right)_{7} \mathrm{COOH} \text { dan oleylamine }} \mathrm{Fe}_{3} \mathrm{O}_{4} \ldots . .(1)}
$$

\section{HASIL DAN PEMBAHASAN}

Hasil sintesis berupa larutan yang hitam pekat, seperti tampak pada Gambar 2, bersifat magnetik, larut dalam asam dan tidak larut dalam air, sifat-sifat ini sesuai dengan sifat-sifat $\mathrm{Fe}_{3} \mathrm{O}_{4}$.

\section{Analisa PSA}

PSA melakukan pengukuran particle size menggunakan prinsip Dynamic Light Scattering. Dalam pengukuran ini yang diukur adalah gerak Brownian partikel dalam medium dan mengkorelasikannya dengan ukuran partikel tersebut. Prinsip kerjanya yaitu dengan mengiluminasikan cahaya laser dan menganalisa fluktuasi intensitas dari cahaya yang terhambur oleh partikel.
Pada penelitian ini digunakan pelarut heksana yang mempunyai refractive index 1,37 dan viscositas 0,29. Dari data PSA diperoleh ukuran partikel seperti pada Tabel 1.

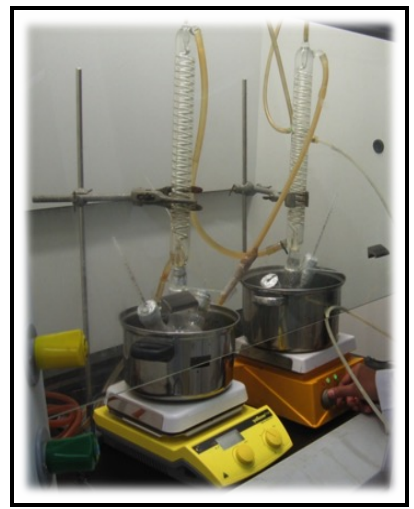

Gambar 1. Proses sintesis magnetit $\left(\mathrm{Fe}_{3} \mathrm{O}_{4}\right)$

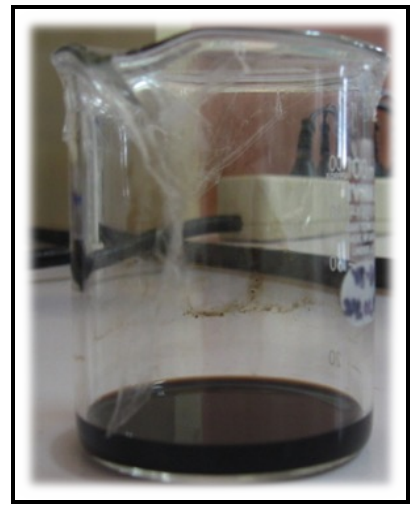

Gambar 2. Hasil sintesis nanopartikel magnetit $\left(\mathrm{Fe}_{3} \mathrm{O}_{4}\right)$

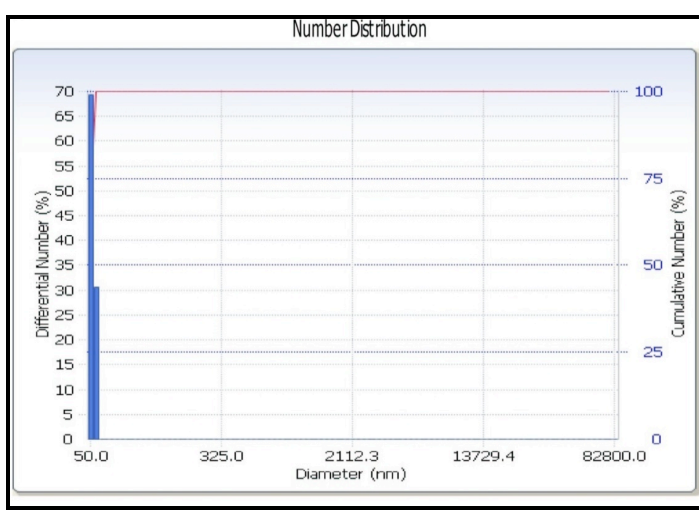

Gambar 3. Gambar distribusi nanopartikel besi 
Tabel 1. Ukuran partikel besi dengan pengukuran PSA

\begin{tabular}{|c|c|c|c|c|c|c|c|}
\hline$\Gamma(1 / \sec )$ & $\mathrm{d}(\mathrm{nm})$ & $f(\%)$ Int. & f(cum.\%)int. & $f(\%) \vee o l$. & 6) Vol. & $f(\%)$ No. & f(cum.\%)No \\
\hline 20038.1 & 50.0 & 7.8 & 7.8 & 0.1 & 0.1 & 69.27 & 69.27 \\
\hline 18592.7 & 53.9 & 5.5 & 13.3 & 0.0 & 0.1 & 30.72 & 99.99 \\
\hline 17251.5 & 58.1 & 0.0 & 13.3 & 0.0 & 0.1 & 0.00 & 99.99 \\
\hline 16007.0 & 62.6 & 0.0 & 13.3 & 0.0 & 0.1 & 0.00 & 99.99 \\
\hline 14852.3 & 67.5 & 0.0 & 13.3 & 0.0 & 0.1 & 0.00 & 99.99 \\
\hline 13780.9 & 72.7 & 0.0 & 13.3 & 0.0 & 0.1 & 0.00 & 99.99 \\
\hline 12786.8 & 78.4 & 0.0 & 13.3 & 0.0 & 0.1 & 0.00 & 99.99 \\
\hline 11864.4 & 84.4 & 0.0 & 13.3 & 0.0 & 0.1 & 0.00 & 99.99 \\
\hline 11008.6 & 91.0 & 0.0 & 13.3 & 0.0 & 0.1 & 0.00 & 99.99 \\
\hline 10214.5 & 98.1 & 0.0 & 13.3 & 0.0 & 0.1 & 0.00 & 99.99 \\
\hline 9477.6 & 105.7 & 0.0 & 13.3 & 0.0 & 0.1 & 0.00 & 99.99 \\
\hline 8793.9 & 113.9 & 0.0 & 13.3 & 0.0 & 0.1 & 0.00 & 99.99 \\
\hline 8159.6 & 122.8 & 0.0 & 13.3 & 0.0 & 0.1 & 0.00 & 99.99 \\
\hline 7571.0 & 132.3 & 0.0 & 13.3 & 0.0 & 0.1 & 0.00 & 99.99 \\
\hline 7024.8 & 142.6 & 0.0 & 13.3 & 0.0 & 0.1 & 0.00 & 99.99 \\
\hline 6518.1 & 153.7 & 0.0 & 13.3 & 0.0 & 0.1 & 0.00 & 99.99 \\
\hline 6047.9 & 165.7 & 0.0 & 13.3 & 0.0 & 0.1 & 0.00 & 99.99 \\
\hline 5611.6 & 178.5 & 0.0 & 13.3 & 0.0 & 0.1 & 0.00 & 99.99 \\
\hline 5206.8 & 192.4 & 0.0 & 13.3 & 0.0 & 0.1 & 0.00 & 99.99 \\
\hline 4831.2 & 207.4 & 0.0 & 13.3 & 0.0 & 0.1 & 0.00 & 99.99 \\
\hline 4482.7 & 223.5 & 0.0 & 13.3 & 0.0 & 0.1 & 0.00 & 99.99 \\
\hline 4159.4 & 240.9 & 0.0 & 13.3 & 0.0 & 0.1 & 0.00 & 99.99 \\
\hline 3859.3 & 259.6 & 0.0 & 13.3 & 0.0 & 0.1 & 0.00 & 99.99 \\
\hline 3580.9 & 279.8 & 0.0 & 13.3 & 0.0 & 0.1 & 0.00 & 99.99 \\
\hline 3322.6 & 301.5 & 0.0 & 13.3 & 0.0 & 0.1 & 0.00 & 99.99 \\
\hline 3082.9 & 325.0 & 0.0 & 13.3 & 0.0 & 0.1 & 0.00 & 99.99 \\
\hline 2860.5 & 350.3 & 0.0 & 13.3 & 0.0 & 0.1 & 0.00 & 99.99 \\
\hline 2654.2 & 377.5 & 0.0 & 13.3 & 0.0 & 0.1 & 0.00 & 99.99 \\
\hline 2462.7 & 406.8 & 0.0 & 13.3 & 0.0 & 0.1 & 0.00 & 99.99 \\
\hline 2285.1 & 438.5 & 0.0 & 13.3 & 0.0 & 0.1 & 0.00 & 99.99 \\
\hline 2120.2 & 472.5 & 0.0 & 13.3 & 0.0 & 0.1 & 0.00 & 99.99 \\
\hline 1967.3 & 509.3 & 0.0 & 13.3 & 0.0 & 0.1 & 0.00 & 99.99 \\
\hline 1825.4 & 548.9 & 2.1 & 15.4 & 0.0 & 0.1 & 0.00 & 99.99 \\
\hline 1693.7 & 591.5 & 6.5 & 21.9 & 0.0 & 0.1 & 0.00 & 99.99 \\
\hline 1571.5 & 637.5 & 10.9 & 32.9 & 0.0 & 0.1 & 0.00 & 99.99 \\
\hline 1458.2 & 687.1 & 13.1 & 46.0 & 0.0 & 0.1 & 0.00 & 100.00 \\
\hline 1353.0 & 740.5 & 12.0 & 57.9 & 0.0 & 0.1 & 0.00 & 100.00 \\
\hline 1255.4 & 798.1 & 8.1 & 66.0 & 0.0 & 0.2 & 0.00 & 100.00 \\
\hline 1164.8 & 860.1 & 3.4 & 69.4 & 0.0 & 0.2 & 0.00 & 100.00 \\
\hline 1080.8 & 927.0 & 0.0 & 69.4 & 0.0 & 0.2 & 0.00 & 100.00 \\
\hline 1002.8 & 999.1 & 0.0 & 69.4 & 0.0 & 0.2 & 0.00 & 100.00 \\
\hline 930.5 & 1076.8 & 0.0 & 69.4 & 0.0 & 0.2 & 0.00 & 100.00 \\
\hline 863.4 & 1160.5 & 0.0 & 69.4 & 0.0 & 0.2 & 0.00 & 100.00 \\
\hline 801.1 & 1250.7 & 0.0 & 69.4 & 0.0 & 0.2 & 0.00 & 100.00 \\
\hline 743.3 & 1347.9 & 0.0 & 69.4 & 0.0 & 0.2 & 0.00 & 100.00 \\
\hline 689.7 & 1452.7 & 0.0 & 69.4 & 0.0 & 0.2 & 0.00 & 100.00 \\
\hline 639.9 & 1565.7 & 0.0 & 69.4 & 0.0 & 0.2 & 0.00 & 100.00 \\
\hline 593.8 & 1687.4 & 0.0 & 69.4 & 0.0 & 0.2 & 0.00 & 100.00 \\
\hline
\end{tabular}

Size Dist. Table Page No. : $1 / 2$

Dari Tabel 1. terlihat bahwa nanopartikel besi yang telah dibuat mempunyai ukuran $50 \mathrm{~nm}$ hingga 53,9 nm kurang lebih 99\%. Sedangkan dari Gambar 1, distribusi nanopartikel besi yang dihasilkan berada pada ukuran $50 \mathrm{~nm}$. 
Tabel 2. Rata-rata ukuran nanopartikel besi

\begin{tabular}{|c|c|c|c|c|c|}
\hline \multicolumn{3}{|c|}{ Distribution Results (Contin) } & \multicolumn{3}{|l|}{ Cumulants Results } \\
\hline Peak & Diameter(nm) & Std. Dev. & Diameter (d) & :3414.1 & \\
\hline 1 & 51.2 & 1.8 & Polydispersity Index (P.I. & ) 0.454 & \\
\hline 2 & 648.1 & 70.9 & Diffusion Const. $\quad$ (D) & $: 4.351 \mathrm{e}-009$ & $\left(\mathrm{~cm}^{2} / \mathrm{sec}\right)$ \\
\hline 3 & $68,994.9$ & $6,087.2$ & Measurement Condition & & \\
\hline 4 & 0.0 & 0.0 & - & & \\
\hline 5 & 0.0 & 0.0 & Temperature & :25.0 & ("C) \\
\hline Average & 51.3 & 40.8 & $\begin{array}{l}\text { Diluent Name } \\
\text { Refractive Index }\end{array}$ & $\begin{array}{l}\text { :HexaneSure } \\
: 1.3750\end{array}$ & \\
\hline & & & Viscosity & $: 0.2940$ & $(C P)$ \\
\hline Residual : & $1.377 e-002$ & $(0 . K)$ & Scattering Intensty & 12110 & (cps) \\
\hline
\end{tabular}

Tabel 2 memperlihatkan bahwa nanopartikel besi yang dihasilkan mempunyai ukuran rata-rata $51,3 \mathrm{~nm}$ dengan standar deviasi 40,8.

Pembuatan nanopartikel magnetit $\left(\mathrm{Fe}_{3} \mathrm{O}_{4}\right)$ dengan metode dekomposisi termal dilakukan hingga temperatur mencapai $280^{\circ} \mathrm{C}$ dengan menggunakan precursor $\mathrm{Fe}(\mathrm{III})$ acetylacetonate $2 \mathrm{mmol}$. Proses dekomposisi termal dari Fe(III) acetylacetonate hingga $280^{\circ} \mathrm{C}$ menghasilkan sumber besi $(\mathrm{Fe})$ dan monomer oksigen untuk menumbuhkan inti $\mathrm{Fe}_{3} \mathrm{O}_{4}$ dengan distribusi ukuran nanopartikel yang beragam. Penambahan dodecanediol berfungsi sebagai growth agent sedangkan asam oleat dan oleylamine ditambahkan untuk menstabilkan larutan dan mencegah terjadinya penggumpalan atau difusi yang tidak terkontrol. Diphenylether berfungsi sebagai pelarut. Campuran yang berwarna coklat kemerahan direflux dan distirrer agar bercampur sempurna dan homogen hingga mencapai temperatur $280^{\circ} \mathrm{C}$ selama kurang lebih 1 jam 45 menit. Aliran gas $\mathrm{N}_{2}$ secara kontinyu dilakukan untuk mencegah terjadinya oksidasi.

Selama pertumbuhan inti $\mathrm{Fe}_{3} \mathrm{O}_{4}$, molekulmolekul asam oleat dan oleylamine akan menstabilkan pertumbuhan partikel-partikel nano dan mencegah terjadinya agregasi partikel yang disebabkan adanya gaya Van der Waals dan gaya magnetik. Pemanasan hingga $280^{\circ} \mathrm{C}$ menghasilkan larutan emulsi coklat kehitaman yang pekat, kental dan lengket sehingga larutan sulit untuk dipindahkan dari labu leher tiga ke dalam erlenmeyer. Penambahan $200 \mathrm{ml}$ etanol akhirnya dilakukan dalam labu leher tiga dan dalam kurun waktu kurang lebih 20 menit, terjadi pengendapan larutan yang cukup banyak. Filtrat yang dipisahkan ditambahkan lagi dengan $200 \mathrm{ml}$ etanol dan didiamkan selama kurang lebih 1 jam dengan harapan masih akan terjadi

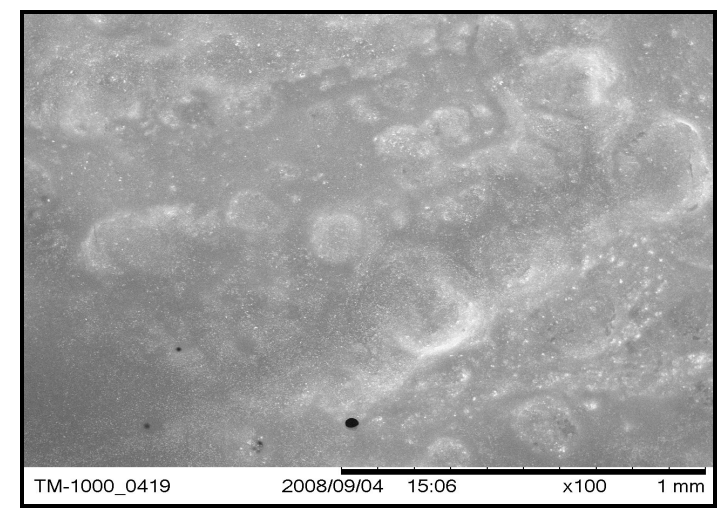

Gambar 4. Foto SEM produk $\mathrm{Fe}_{3} \mathrm{O}_{4}$ nano partikel dengan panjang bar skala adalah $1 \mathrm{~mm}$

pengendapan. Hasilnya terjadi endapan yang cukup kemudian ke dalam endapan tersebut ditambahkan lagi dengan heksana, asam oleat dan oleylamine.

\section{Analisa SEM}

Analisa dengan menggunakan SEM pada prinsipnya adalah menggunakan elektron yang direfleksikan dari permukaan preparat atau sampel untuk menghasilkan gambar. Dimana gambar yang dihasilkan berupa gambar tiga dimensi. Analisa morfologi partikel dilakukan dengan SEM. Pada Gambar 4 tampak bahwa partikel $\mathrm{Fe}_{3} \mathrm{O}_{4}$ yang disintesis menunjukkan morfologi yang jelas dan masih berupa aglomerat.

\section{KESIMPULAN}

Proses dekomposisi termal dari $\mathrm{Fe}(\mathrm{III})$ acetylacetonate hingga $280^{\circ} \mathrm{C}$ menghasilkan $\mathrm{Fe}_{3} \mathrm{O}_{4}$ dengan distribusi ukuran nanopartikel 
yang beragam. Diameter partikel $\mathrm{Fe}_{3} \mathrm{O}_{4}$ yang terbentuk berukuran 50,0 nm hingga $53,9 \mathrm{~nm}$. Bilangan distribusi tertinggi berada pada diameter 50,0 nm dengan distribusi $69,27 \%$, sehingga diameter partikel rata-rata sebesar $51,3 \mathrm{~nm}$.

\section{DAFTAR PUSTAKA}

Berry, C. 2009. Progress in functionali-zation of magnetic nanoparticles for applications in biomedicine. Journal of physics $d$ applied physics 42(22): 2240.

Brydson, R.M and C. Hammond. 2005. Genetic methodologies for nano-technology characterization. Nano-scale science and technology. John Wiley \& Sons.

Gözüak, F., Y. Köseoğlu, A. Baykal, and H. Kavas. 2009. Synthesis and characterization of $\mathrm{CoxZn1-xFe} \mathrm{O}_{4}$ magnetic nanoparticles via a PEGassisted route. Journal of magnetism and magnetic materials 321 (14): 2170-2177

Guin, D. and S.V. Manorama. 2008. Room temperature synthesis of nearly monodispersed $\mathrm{Fe}_{3} \mathrm{O}_{4}$ nanoparticles. Materials letters 62: 3139-42.

Obaidat, I.M., B Issa, and Y. Haik. 2011. The role of aggregation of ferrite nanoparticles on their magnetic properties. Journal of nanoscience and nanotechnology 11(5): 3882-3888.

Singh, J. 2004. Modern physics for engineers. Weinheim: Wiley-VCH Verlag GmbH \& Co. 